\title{
Argentina: Impacts of the child allowance programme on the labour-market behaviour of adults
}

\author{
Roxana Maurizio and Gustavo Vázquez
}

ABSTRACT

In 2009 Argentina implemented the Universal Child Allowance for Social Protection (AUH),

a cash transfer programme for households with children. Coverage provided by the contributory family allowance programme was extended to parents who are unemployed or who work in the informal sector (domestic workers, for example). This paper uses the difference-in-difference estimator and propensity score matching techniques to evaluate the short-term effects of the AUH on adult labour participation and income generation. The results suggest that, during its first year of operation, no significant disincentives to work were generated by the programme, given that it did not discourage adults from working or lead to a reduction in the number of hours worked. These findings are highly relevant in the Latin American context where these kinds of cash transfers have become an important component of social protection systems. 


\section{I}

\section{Introduction}

In 2009 Argentina implemented a major cash transfer programme for children and adolescents called Universal Child Allowance for Social Protection (AUH, Asignación Universal por Hijo para Protección Social), which extended the coverage of the contributory family allowance programme to new segments of the population.

The AUH is a monthly cash transfer paid to a parent, guardian or relative (up to the third degree of consanguinity) for each child under 18 years of age. In the case of children with disabilities, the age limit is not applicable. The AUH is a semi-conditional cash transfer: $80 \%$ of its value is paid on a monthly basis to the beneficiary, and the remaining $20 \%$ is deposited into a savings account in their name. The latter sum may be withdrawn once the beneficiary has provided evidence of school attendance and medical check-ups. AUH beneficiaries may not claim any other social benefit provided by the national government, by provincial or municipal governments or by the Autonomous City of Buenos Aires, and all earlier programmes targeting similar groups were phased out.

Several studies conducted ex-ante evaluations simulating the impact of the AUH on inequality, poverty and extreme poverty indicators. ${ }^{1}$ They all arrive at the conclusion that, once the entire target population has been reached, AUH implementation would significantly reduce indigence and, to a lesser extent, poverty, while also having a positive effect on inequality. Nevertheless, these studies do not take into account the possible impact of these transfers on adults' decisions to work and on the number of hours they work.

$\square$ The valuable comments and suggestions of Fabio Bertranou, Rafael Rofman and Luis Beccaria are very much appreciated. We also thank the two anonymous reviewers for their valuable comments.

1 These include Roca (2010); Agis, Cañete and Panigo (2010); Gasparini and Cruces (2010), ILO (2010); and Bertranou and Maurizio (2012).
The present study proposes to fill this gap by carrying out an ex-post evaluation of the AUH. Through the application of a non-experimental econometric strategy, we evaluate the short-term impact of the AUH on economic participation decisions, employment, unemployment, number of hours worked and income generation. Hence, this study contributes to enrich the scant but growing literature on the impact of cash transfers on the labour-supply behaviour of adults in developing countries.

On the basis of the results obtained, we cannot conclude that the programme generated any disincentives to work among the adult members of beneficiary households between 2009 and 2010, in terms of encouraging them to leave the labour force or cut back on the number of hours worked.

However, at least four caveats apply to our results. First, unlike other studies that perform impact assessments as part of their evaluation of this kind of programme, no surveys have been specifically designed for this purpose in Argentina. Second, in the household survey employed, AUH beneficiaries are only indirectly identified. Third, differences in unobserved characteristics might arise between the treatment and control groups, although the methodology employed aims to reduce the likelihood of this problem. Lastly, the analysis covers a relatively short period of time, and the results could change over a longer time horizon, particularly in terms of the programme's impact on labour-market participation.

Section II of this article provides a brief description of the main characteristics of the programme. Section III then presents the theoretical framework and a review of the empirical evidence for Latin America. Section IV details the source of information employed, while section $\mathrm{V}$ specifies the econometric strategy. Section VI provides some descriptive statistics and section VII discusses the impacts on labour-market outcomes. Lastly, section VIII offers some concluding remarks. 


\section{II}

\section{Brief description of the programme}

Given the greater incidence of poverty among children and adolescents compared to other age groups, Latin American countries have been implementing and expanding non-contributory cash transfer programmes (conditional cash transfer programmes) to households with children and adolescents since the mid-1990s. They have gradually become important mechanisms within social policies and regional poverty reduction strategies.

In November 2009 the Argentine government implemented a major cash transfer programme for children called Universal Child Allowance for Social Protection (AUH). This extended the coverage of the contributory family allowance programme to include the children of:

(i) workers not registered in the social security system (informal workers) or domestic workers whose labour income is below the minimum wage;

(ii) monotributistas sociales, ${ }^{2}$

(iii) unemployed persons without unemployment insurance, and

(iv) economically inactive workers without pensions. Two groups of workers were excluded from AUH despite the fact that they do not receive any contributory benefits: domestic workers whose wages exceed the minimum wage, and workers registered in the monotributo scheme, except for those in the monotributo social.

The AUH is a cash transfer that is paid on a monthly basis to a parent, guardian or relative (up to the third degree of consanguinity) for every child under 18 years of age. The age limit is not applicable in the case of children with disabilities. The children must be Argentine nationals or have been resident in the country for at least three years. Both the children and the parents must have a national identity document. When parents share custody, the programme gives priority to mothers as beneficiaries. The benefit is a set amount per child and it can be claimed for up to five children in one's charge. Its initial value was 180 pesos (US\$ 47) per child and 720 pesos for a

\footnotetext{
2 The monotributo is a simplified tax regime under which the worker pays a single fixed amount (whose value depends on the income declared), which includes a social security component and a tax component. The monotributo social is a tax category for individuals in a socially vulnerable situation who are part of labour cooperatives or production projects of up to three people, and whose income falls below a certain level.
}

child with disabilities (four times the standard benefit). It was later updated to take into account the erosion of its purchasing power by inflation.

At present, the AUH covers about $30 \%$ of children (3.5 million) and $15 \%$ of households ( 1.8 million) in Argentina. Government expenditure on the programme represents approximately $0.8 \%$ of GDP, making it one of the largest programmes in the region.

Receiving any other type of social benefit is incompatible with the AUH, and all earlier programmes targeting similar groups were phased out. In particular, the new policy replaced the Unemployed Heads of Household Plan and the Family Programme for Social Inclusion, the two most important Argentine conditional cash transfer programmes of the 2000s. As a result of this, in its initial stages the AUH absorbed significant flows of individuals that were former beneficiaries of these two programmes.

The AUH is a semi-conditional cash transfer programme: $80 \%$ of its value is paid on a monthly basis to beneficiaries, while the remaining $20 \%$ is deposited into a savings account in their name. The latter sum may be withdrawn once the holder has provided evidence of completion of the vaccination programme and relevant health checks in the case of children under 5 years of age, and has presented a certificate of school-year completion for school-age children. ${ }^{3} \mathrm{AUH}$ conditionality is therefore similar to that of most conditional cash transfer programmes implemented in Latin America.

Even though reducing poverty and extreme poverty is one of its objectives, the AUH is not an ad-hoc programme designed to alleviate the situation of families with socially vulnerable children, as in the case of the Bolsa Família programme in Brazil or the Oportunidades programme in Mexico. As mentioned above, it is an extension of the existing contributory child allowance

\footnotetext{
3 The regulations of the programme establish that the AUH monthly payment will be suspended if certificates are not duly presented, and $20 \%$ of the bank deposit will be withheld until the situation is regularized. In some cases, parents were unable to comply with the conditionalities because there were no health centres nearby or because they could not get an appointment with the doctor to certify the health check-ups (Pautassi, Arcidiácono and Straschnoy, 2013). For this reason, checks on compliance with conditionalities were not exhaustive in the early stages of the programme, and only became more rigorous as time went by.
} 
programme covering the children of formal workers, unemployed persons with unemployment insurance and pensioners. The amount received is, in fact, the same in both systems.

This point is important because, unlike a means-tested conditional cash transfer programme, the restrictions imposed by the AUH are not directly related to family incomes but rather to the employment status of the adults in charge of the children, and to their labour incomes if they are employed (in informal jobs). However, the difficulties involved in monitoring informal labour incomes hamper the enforcement of such restrictions.

\section{III}

\section{Theoretical framework and empirical evidence}

\section{Theoretical framework}

There is a broad debate surrounding the impact that cash transfers to households may have on adults' labour behaviour. Such impacts concern receipt of non-labour incomes, on the one hand, and fulfilment of programme conditionality, on the other.

The neoclassical theory of individual labour supply provides that this type of non-labour income produces a pure income effect in the household, which leads to an increase in the demand for normal goods. If leisure is a normal good then the supply of labour will decrease, a behaviour that could lead to labour-market exits (corner solution) or to a reduction in the number of hours worked (interior solution).

Nevertheless, it could be argued that the actual impact of the cash transfer will depend on its magnitude. Other factors could affect the decision to remain in or leave the labour force in response to such benefits, such as the characteristics of the occupation other than its remuneration (job conditions, commuting distance or number of hours worked) or the demands of care and household chores.

While transfers might discourage labour participation if they are of a high enough value, the opposite effect is also possible. In other words, this benefit might allow households to overcome entry barriers to certain productive or entrepreneurial activities or to implement certain economic decisions that would otherwise be impossible (Medeiros, Britto and Veras Soares, 2008; Teixeira, 2010).

In the more complex family labour supply model (Killingsworth, 1983), decisions regarding time allocation are linked to the decisions of other household members. Hence, a second channel may be introduced through which transfers might lead to changes in the labour supply behaviour of adults, that is, the impacts associated with fulfilment of the programme's conditionalities. By being linked to school attendance, the benefit reduces the opportunity cost of study, which might lead to a decline in the demand for study-substitute goods and to an increase in the demand for study-complementary goods. If work is a substitute for study, this will lead to a reduction in the child labour supply. However, if work and study are not perfect substitutes, the impact on child labour supply could be ambiguous (Ravallion and Wodon, 2000).

This raises two important points regarding the adult labour supply. One is the question of how the labour supply of the other household members would react to a reduction in the labour supply of children. This behaviour might partially offset the impact of the transfers on total household incomes, causing the potential disincentive effect on adults to be fairly small. Skoufias and Parker (2001) point out that the impact of these transfers will vary between households depending on their personal circumstances. In particular, for certain types of households, the amount of the transfer might be lower than the loss of income caused by the reduced labour supply of children once they start going to school, thus discouraging enrolment in the programme.

Second, fulfilment of conditionality could itself alter the time allocation of adults: if school attendance reduces the time spent on childcare, this could increase the time available for work; conversely, the time needed to ensure school attendance and medical check-ups could reduce the time spent working (Parker and Skoufias, 2000).

The distribution of time and tasks within households is thus another central aspect of these types of transfers, and these factors become even more relevant from a gender perspective. As pointed out by Gammage (2010), the potential effects of the programme on women's allocation of time between paid and unpaid work must be taken into account when analysing the results of these programmes, since responsibility for the tasks derived from programme conditionalities usually falls to women. 
Lastly, the fact that these programmes have an "exit door" associated with improvement of the household's economic conditions might discourage participation in the labour market since it could affect eligibility to continue in the programme. In the case of the AUH, gaining access to and remaining in the programme do not depend on family income but rather on the labour incomes of the adults in charge of the children. However, monitoring compliance with this restriction is fairly difficult in a context of labour informality, which might weaken the significance of the types of behaviours that tend to reduce the labour supply. In the case of unemployed or economically inactive individuals, the AUH does not create any explicit disincentives to work. A formal job would give them access to a contributory child allowance, while an informal job would allow them to continue receiving the AUH. Moreover, the benefit consists of a fixed amount per child and does not depend on the level of labour incomes. All of these particular characteristics of the AUH might lessen the potential impact of the transfer on work-related decisions.

\section{Empirical evidence for Latin American countries}

An increasing number of studies are analysing the impact of conditional cash transfer programmes on adult labour-market behaviour in Latin America. However, the empirical evidence is not conclusive.

The results obtained by Ferro and Nicollela (2007) for the Brazilian programme Bolsa Família suggest that it did not have a disincentive effect on the labour supply although it did on the number of hours worked, but the aggregate impact seems to have been rather small. In particular, while beneficiary mothers living in urban areas work 1.5 hours per week more than non-beneficiary mothers, mothers and fathers in rural areas exhibit the opposite behaviour. The reduction in the number of hours worked might be a result of having to allocate more time to compliance with programme conditionality or to housework previously done by children. The potential income effect of the transfers may have played a part as well. A subsequent study by Ferro, Kassouf and Levison (2010) found similar results: the programme led to an increase in the economic participation of mothers and fathers in urban areas but had no significant effects in rural areas.

Foguel and Paes de Barros (2010) find that the programme had null effects on the economic participation of women and a small impact among men. Regarding the number of hours worked, they find a negative effect of minor magnitude for women and no significant effects for men.

Medeiros, Britto and Veras Soares (2008) find that female heads of household who are beneficiaries of this programme are less likely to participate in the labour market than non-beneficiaries. No significant effects were found for other groups. The results obtained by Teixeira (2010) also suggest an average null effect of the Bolsa Família programme on the probability of working and a very small reduction in the number of hours worked by adults. The elasticity of response is greater among women and informal workers, and it increases with the size of the benefit.

Conversely, Soares, Ribas and Osório (2007) find an increase in the participation rates of men and women associated with the Bolsa Família programme, with more variation among women. Along the same lines, Tavares (2008) finds that the likelihood of working rises by around $6 \%$ for beneficiary mothers, while the number of hours they work per week increases by $2 \%$.

In the case of Mexico, Parker and Skoufias (2000) find that the Progresa programme (now the Oportunidades programme) has no disincentive effects on adults' workrelated decisions. A more detailed analysis of women's allocation of time reveals that the programme led to an increase in the number of hours spent on meeting the conditionality requirements. On the other hand, the programme has no significant effects on the number of hours spent on leisure by men or women. The results obtained by Skoufias and Di Maro (2008) confirm that the Mexican programme does not create disincentive effects.

Amarante, Ferrando and Vigorito (2011) found a similar pattern is found in Uruguay, where the introduction of the National Social Emergency Plan (PANES) did not lead to changes in the labour supply or in the number of hours worked.

Soares, Ribas and Hirata (2008) analyse the impact of Paraguay's Tekoporã programme. They find that the programme has a negative impact on the labour supply of men, which is even stronger in moderately poor and in rural areas. However, when temporary workers are excluded, this negative impact remains only in moderately poor areas. Non-significant effects were found for women and for the population as a whole.

Galasso (2006) analyses the impact of the Chile Solidario programme during its first two years of operation. The author finds that, even though access to this benefit resulted in greater participation in employment programmes, which might improve employability in the medium term, the overall proportion of employed members in beneficiary households does not seem to have 
increased in the short term. Only in rural areas does the author find a rise in the labour force participation rate. In any case, the author highlights that "the short term horizon of the current analysis might not be sufficient to observe any impact along these dimensions".

Alzúa, Cruces and Ripani (2010) conduct a comparative evaluation of transfer programmes in Honduras, Mexico and Nicaragua. Again, the authors find that decisions regarding labour participation and working hours are unaffected by these transfers, apart from in Nicaragua, where they found a reduction in the number of hours worked at the household level, especially where the head of household is female. In fact, the authors find that the Progresa programme had positive effects on men's hourly wages and on total

\section{IV}

\section{Data}

The data employed in this paper come from the regular household survey of Argentina, the Permanent Household Survey (PHS) carried out by the National Institute of Statistics and Censuses (INDEC), which covers 31 urban areas and collects information on labour-market variables in particular.

Even though the PHs is not a longitudinal survey and does not include retrospective questions, its rotating panel sample enables flow data to be drawn from the survey, that is, a selected household is interviewed in four moments or waves: the household appears in the sample for two successive quarters, followed by a break for the following two quarters, and appears again in two successive quarters, one year later. By comparing the situation of an individual in a given wave to that labour incomes in beneficiary households, suggesting the presence of indirect impacts on local labourmarket conditions.

Lastly, Garganta and Gasparini (2012) evaluate the effects of the AUH on transitions between formality and informality. They conclude that the programme significantly discourages the formalization of beneficiaries, but found no evidence of incentives for registered wage earners to become informal workers.

It is possible to conclude, therefore, that assessment of the impact of the AUH programme is an empirical matter. However, the more recent evidence for Latin American countries suggests that cash transfers have no significant disincentive effects on the labour-market insertion of adult beneficiaries.

of the same individual in another wave, it is possible to determine whether the person has experienced changes in diverse variables, including occupational and demographic ones.

In particular, annual panel data constructed for the QI2009-QIII2010 period are employed in this study so as to include information prior and subsequent to implementation of the AUH in November 2009. ${ }^{4}$ To ensure that a greater number of observations were available, a pool with these three annual panels was constructed.

\footnotetext{
${ }^{4}$ Data from the fourth quarter of 2009 were excluded because the programme was launched in November of that year and this quarter already includes information on the programme's beneficiaries.
}

\section{V}

\section{Approach and methodology}

\section{Econometric specification}

To evaluate the impacts of the AUH, a non-experimental method will be employed. This method is based on the application of matching techniques to define a control group, making it possible to estimate what the situation of beneficiaries would have been had they not gained access to the programme. Then, having accurately defined the control group and by comparing outcome variables between the beneficiary and non-beneficiary groups, it is possible to attribute the observed differences to the particular policy under study. 
Following the traditional terminology of this approach, $D$ is defined as a variable that indicates receipt of the transfer $(D=1$ if the household/person receives the transfer; $D=0$ if not), and $Y$ is the outcome of interest $\left(Y^{1}\right.$ being outcome in the presence of the benefit, and $Y^{0}$ in its absence). The impact of the transfer is measured by the average treatment effect on the treated (ATT), which is conditional on a propensity score model, $\mathrm{P}(\mathrm{X})$, where $\mathrm{X}$ represents a vector of observable characteristics:

$$
\operatorname{ATT}(X)=E\left[Y^{1}-Y^{0} / P(X), D=1\right]
$$

where $E[$.$] is the expectation of the difference between$ the two outcomes, with and without the treatment, over the population receiving the transfer $(D=1)$.

Since the counterfactual, $E\left[Y^{0} / P(X), D=1\right]$, is not an observable situation, propensity score matching techniques are employed to estimate it. Given that only the ATT needs to be identified, it is sufficient to verify the assumptions suggested in Heckman, Ichimura and Todd $(1997,1998)$ (i) "Ignorability of treatment in the sense of conditional mean independence"; and (ii) "Matching condition". The first condition implies that the selection of treated and control groups is made purely on the basis of the propensity score, and then, after accounting for it, the assignment to treatment is independent of mean outcomes; the second condition ensures that for every possible value of propensity score there exist beneficiary and non-beneficiary control cases.

To estimate the ATT parameter, a difference-indifference matching estimator (DD) will be implemented on the basis of the available information from before and after policy implementation, through comparing the temporal changes of the outcome variable in the beneficiary group with the changes in the same variable in the control group. The advantage of this strategy lies in the possibility to control for biases derived from time invariant unobserved characteristics. Its expression is given by,

$$
\begin{aligned}
& \widehat{A T T^{D D}}=\frac{1}{n^{1}} \sum_{\substack{\left.i=1 \\
n_{i}=1\right\}}}^{n^{1}} Y_{i, t_{1}}^{1}\left(X_{i, t_{1}}\right)-Y_{i, t_{0}}^{1}\left(X_{i, t_{0}}\right)- \\
& \widehat{E}\left[Y_{i, t_{1}}^{0}\left(X_{i, t_{1}}\right)-Y_{i, t_{0}}^{0}\left(X_{i, t_{0}}\right) / P\left(X_{i, t_{0}}\right), D_{i}=0\right]
\end{aligned}
$$

where $n^{1}$ represents the quantity of cases that receive the benefit, $t_{0}$ is the moment prior to programme implementation, and $t_{1}$ the moment after implementation.

Hence, by adapting assumptions (1) and (2) to the context of this estimator, the following expressions are derived:

$$
\begin{gathered}
E\left[Y_{t_{1}}^{0}(X)-Y_{t_{0}}^{0}(X) / P(X), D=1\right]= \\
E\left[Y_{t_{1}}^{0}(X)-Y_{t_{0}}^{0}(X) / P(X), D=0\right] \\
0<\operatorname{Pr}(D=1 / X)<1
\end{gathered}
$$

Lastly, we focus our attention on estimation of the ATT parameter on the support region common to both beneficiaries and the control group. To estimate the counterfactuals, two alternatives of matching are applied: nearest neighbour $(\mathrm{NN})^{5}$ and local linear regression (LLR). ${ }^{6}$

\section{Strategies for identifying the treatment group and the control group}

The basis for this study is the correct identification of AUH beneficiary households (treatment group) and those that will constitute the control group.

Unfortunately, the PHS does not inquire about this matter directly so identification must be addressed indirectly. In order to identify households receiving the AUH in 2010 we resorted to a question that captures the sum of cash transfers received by household members from, for example, the government, private institutions and the Church. Given that the question includes a rather wide range of entities, it cannot be assumed that the answers relate exclusively to this programme. Therefore,

\footnotetext{
${ }^{5}$ Under this alternative, the counterfactual for each case treated is estimated using a simple average of the outcomes for a subset of cases belonging to the control group, whose conditional probability of receiving the benefit is similar on the basis of a set of observable attributes. Here, each subset is composed of the five nearest "neighbours". 6 In this case, each counterfactual is estimated on the basis of a weighted average of outcomes for a subset of cases in the control group assigned to each beneficiary unit, in terms of the proximity measure mentioned in footnote 5 . The weights are thus built to assign greater importance to the comparison units closest to the respective beneficiary case, and are estimated for each subgroup using weighted linear regressions of the outcome for a constant and the difference between estimated propensity scores and that for each beneficiary case. The weightings used for the regressions use a kernel function whose arguments are given by the measure of proximity used, and the bandwidth or smoothing parameter chosen (a concept analogous to the number of "neighbours" used in the first alternative). Fan (1992) analyses the properties of this estimator compared to other traditional linear smoothers and concludes that it is the most efficient in asymptotic terms and in finite samples, and it adapts to different design densities of the data.
} 
households were initially classified as AUH beneficiaries only when the amounts declared matched the values established by the programme, i.e. the amount of the transfer was used as treatment indicator.

Considering the frequency of the cash values appearing in this question it may be assumed that some households declared the amount that was actually received on a monthly basis as benefit ( $80 \%$ of the sum of the benefit), while others declared the full amount. The values of the AUH per number of children in one's charge in the period under analysis are shown in table 1.

TABLE 1

Value of the AUH, by number of children (Argentine pesos)

\begin{tabular}{lcc}
\hline \multirow{2}{*}{$\begin{array}{l}\text { Number of } \\
\text { children }\end{array}$} & \multicolumn{2}{c}{ Value of the AUH } \\
\cline { 2 - 3 } & Total & $80 \%$ \\
\hline 1 & 180 & 144 \\
2 & 360 & 288 \\
3 & 540 & 432 \\
4 & 720 & 576 \\
5 & 900 & 720 \\
\hline
\end{tabular}

Source: prepared by the authors on the basis of data from the Permanent Household Survey of the National Institute of Statistics and Censuses (INDEC).

However, values close to the amount of the benefit were also considered as AUH in order to account for the possibility of errors in income statements and the fact that households tend to round off the amounts declared. In order to minimize the possibility of misclassification, the frequency of each of these values in 2010 was compared to 2009 (before AUH implementation) so as to verify that values considered as AUH were not present in the year before implementation. This procedure clearly showed that the values corresponding to AUH transfers started to appear as payments made by other national programmes begun to disappear (this applies to the Unemployed Heads of Household Plan, the Family Programme for Social Inclusion and Training and Employment Insurance) owing to the fact that the AUH cannot be delivered in conjunction with any other type of social benefit (see figure 1). ${ }^{7}$

Also, when the values observed suggested that more than one person per household was receiving the

\footnotetext{
7 Based on figure 1, it seems reasonable to assume that values such as 140 pesos and 280 pesos also correspond to the AUH, because they first appear in 2010 and because the amounts are very similar to those established by the programme (144 pesos and 288 pesos, respectively).
}

$\mathrm{AUH}$, the total amount of the benefit received by the household was compared to the number of children in the household. Since several cases were found in which the amount of the benefit erroneously appeared for more than one adult member, we excluded from the analysis households with more than one recipient member and those whose total AUH incomes suggested the presence of more children than the number actually living in the household. ${ }^{8}$

In addition, the group of households classified as beneficiaries was further reduced by excluding those without children. This responded to the need to reduce the heterogeneity of this group in relation to the control group, which was made up of AUH-eligible households (which therefore contain children).

The eligible households (control group) are those that meet all the requirements to receive the AUH but do not receive it. As already mentioned, potential beneficiaries are:

(i) households with children under 18 years old whose heads or spouses are non-registered wage earners (informal workers) or domestic workers whose incomes fall below the minimum wage;

(ii) monotributistas sociales;

(iii) unemployed persons not in receipt of unemployment insurance, and

(iv) economically inactive workers without pensions

Therefore, the analysis will be limited to those households (and their members) with children that were eligible for the AUH in 2009, differentiating between them according to whether they gained access to the benefit in 2010 (treated group) or not (control group). Thus, the eligibility condition corresponds to 2009 , but the recipient condition corresponds to 2010.

Households with incomplete information or with imputed values for individual or family incomes were excluded from the sample. In addition, outlier values of total family incomes and their components (labour and non-labour incomes) were dropped from the analysis using a robust data standardization method.

Since we are interested in evaluating the effects of the AUH on adult labour-market behaviour, the sample in the analysis of individuals is comprised of people

\footnotetext{
${ }^{8}$ These households represented $3 \%$ of the total number of households initially classified as AUH beneficiaries. Even though this would mean that some households are excluded from the analysis in spite of having correctly declared more than one beneficiary per household, the comparison between the actual number of children living in the household and the number derived from the total sum of the benefit per household suggests that the error of including these cases would be more significant than the error of excluding them.
} 


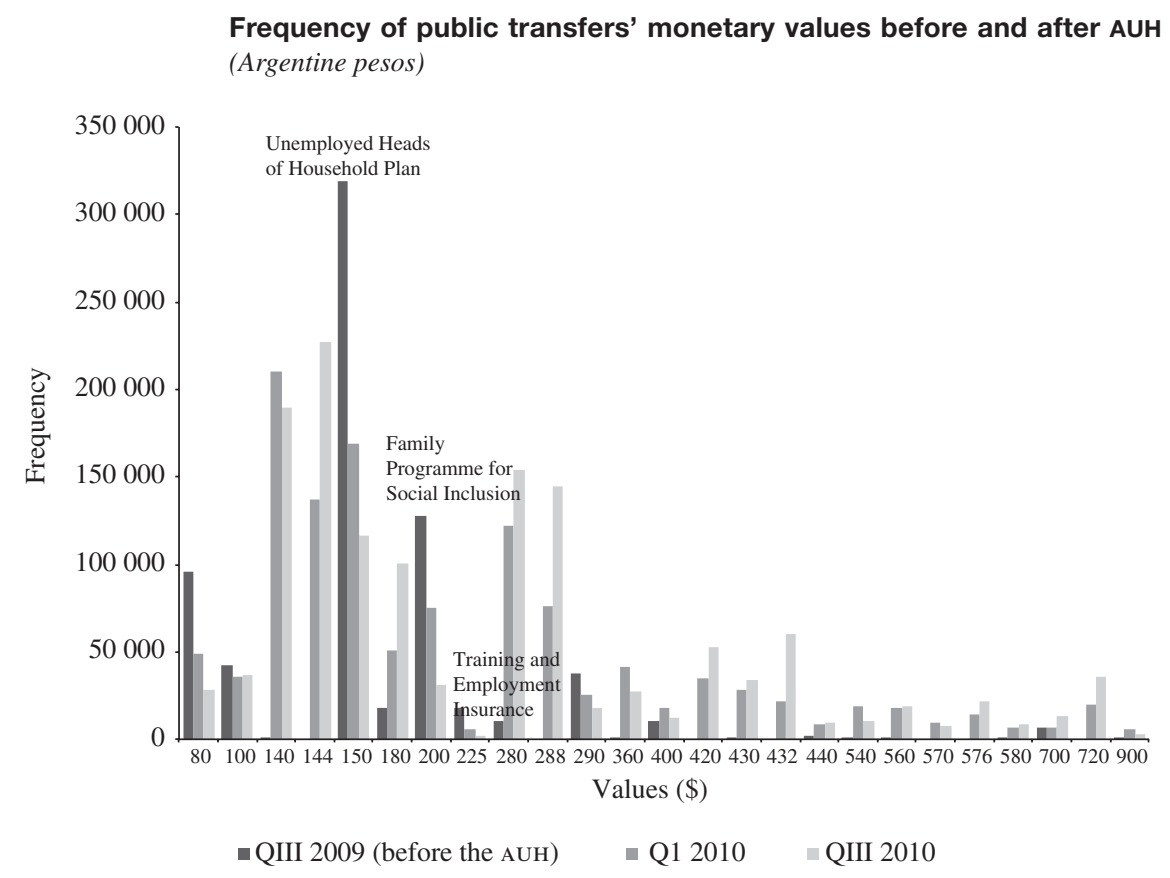

Source: prepared by the authors on the basis of data from the Permanent Household Survey of the National Institute of Statistics and Censuses (INDEC).

in economically active age groups: men aged between 18 and 64 years, and women aged between 18 and 59 years. In both cases, the upper age limit corresponds to the legal retirement age.

Before concluding this section, some points must be clarified regarding the composition of the eligible households group. Given that the AUH aims to achieve universal coverage for households with children not covered by the contributory system, it is curious that a group of households remained outside the AUH programme during its first year, despite being eligible. Even though the causes of this phenomenon are not entirely known, certain factors might have played a role.

First, as mentioned earlier, in order to enter the AUH programme, both children and the parents must have national identity documents that serve as a proof of identity. According to some qualitative studies, this requisite seems to have represented a major barrier to programme access, at least in its early stages. Delays in enrolling the newborn in the programme in firstchild households might have also been another reason for not entering the programme. Other family issues might also have played a part (Pautassi, Arcidiácono and Straschnoy, 2013).
In addition, some individuals who might appear to qualify for the benefit according to the PHS are in fact registered as monotributistas, and as such are not eligible for the programme. However, since it is impossible to identify this group in the survey, they remained in the eligible group in the analysis.

As was also discussed above, programme impact can vary according to households' constraints and preferences (Moffit, 2002; Skoufias and Parker, 2001). In particular, eligible households might exclude themselves from the programme owing to certain administrative procedures or requisites associated with the conditionalities imposed for programme access.

It is important to mention that compliance with conditionalities is not being used to determine household eligibility. This is for two reasons. First, the PHS does not provide complete information on this matter, particularly in terms of health checks. With regard to education, even though the survey does identify whether a child goes to school or not, if the child does not attend school the household does not necessarily become non-eligible, because it can still receive the AUH for another minor that does attend school. However, the minor for whom the household receives the benefit cannot be identified in 
the PHS. In any case, $90 \%$ of eligible households would still be eligible if a restriction was imposed stating that every child living in the household must attend school. Second, enforcement of conditionalities was more lax in the early stages of the programme but became more rigorous over time.

As already mentioned, the evaluation relates to the programme's first year of implementation and thus the existence of a group of non-beneficiary eligible households could also be due to registration delays. The distance between the households and the administrative offices of the programme might have been another factor discouraging enrolment in the early stages, before the implementation of ad hoc measures to reach the most distant population.

Lastly, two additional points need to be made. First, accurately identifying the programme's impact requires the absence of anticipation effects (Ashenfelter's dip), that is, the eligible group must not change its behaviour because it anticipates implementation of the programme. ${ }^{9}$ Given that the announcement of the AUH was totally unexpected, that its implementation took place very fast and that, by November 2009, the first operative month, the programme already covered 3.3 million children and that this number then remained relatively stable at about 3.5 million, it may be assumed that there were no significant anticipation effects on the part of the population aimed at gaining eligibility to access the programme, which could have resulted in selection biases.

Second, unfortunately, given the short-term panel structure of the PHS, it is not possible to control whether households in the treatment and control groups showed similar trends in outcome variables prior to programme implementation, as suggested by, for example, Duflo (2001).

\footnotetext{
9 Ashenfelter (1978); and Heckman and Smith (1999).
}

\section{VI}

\section{Descriptive statistics}

This section presents the characteristics of AUH beneficiaries (treatment group), which are then compared to non-beneficiary eligible households (control group) before programme implementation.

\section{Beneficiary characteristics}

Table A.1 in the annex summarizes the demographic and labour characteristics of AUH beneficiaries and their families in $2010 .{ }^{10}$ For the sake of comparison, the table also includes individuals of economically active ages living in non-beneficiary households. Approximately $58 \%$ of beneficiaries are spouses and $34 \%$ are heads of household. As may be expected, these figures vary

\footnotetext{
10 Even though the PHS data expanded to the whole country shows a total number of beneficiaries that is lower than the total shown by administrative records, the composition of the population in terms of personal variables is very similar in both sources of information. The underestimation of beneficiaries is the result — at least in part - of the fact that the PHS is not specifically designed to identify these types of transfers. At the same time, expanding the survey to the whole country might itself lead to some errors. Nonetheless, some authors such as Galasso and Ravallion (2004) have employed the same source of information to assess the Unemployed Heads of Household Plan, also in a context of beneficiary number underestimation.
}

significantly by gender, since almost $90 \%$ of men are heads of household, while $64 \%$ of women are spouses. Women make up the vast majority of beneficiaries (89\%), which could be at least in part explained by the reassignment of beneficiaries from previous public transfer programmes, which had a high number of women among their beneficiaries. Also, as mentioned above, AUH programme regulations give priority to mothers as beneficiaries. The relatively higher level of informality among women, on average, could also be a factor.

The average age of beneficiaries is 35 , with female beneficiaries being younger than men. Levels of education are quite low in both cases: around 9.4 (men) and 9.6 (women) schooling years. The results for the overall non-beneficiary population at economically active ages are 10.9 and 11.8 years of schooling for men and women, respectively.

With regards to beneficiaries' employment status, a similar proportion of employed and inactive workers was found. However, among women, $52 \%$ are inactive and $42 \%$ are employed, while these figures for men are 5\% and $90 \%$, respectively. On average, female beneficiaries work 27 hours per week and men work 43 hours. Labourmarket participation is thus lower for female beneficiaries, both in terms of activity rates and hourly intensity. 
The average number of members living in beneficiary households (non-beneficiary households) is 4.7 (4.4), while the average number of children is 2.5 (2.0). In spite of the benefit, the incidence of poverty across these households was still very high in 2010: approximately $64 \%$ of beneficiary households were poor, while $18 \%$ were extremely poor. ${ }^{11}$ In the case of non-beneficiary households, these figures were $18 \%$ and $7 \%$, respectively.

Lastly, in 2010 the AUH covered approximately two children per beneficiary household, representing a monthly transfer of about 300 pesos (US\$ 75). This value accounted for around $40 \%$ of total family income net of transfers. Even though this benefit is significant in relation to these households' self-generated income, the poverty gap was still very large even after receiving the benefit (around 40\%).

${ }^{11}$ Households are identified as poor if their total income falls below the poverty line. The poverty line for 2009 and 2010 was constructed by updating the value registered in 2007 using the variation in the official consumer price index surveyed for nine provinces of the country. This decision was based on the controversy surrounding the consumer price index published by the National Institute of Statistics and Censuses (INDEC).

\section{Comparison between beneficiary households and eligible non-beneficiary households in 2009 (baseline)}

As may be observed in annex table A.2, households that became AUH beneficiaries in 2010 had larger families and more children than non-beneficiary households in 2009. Family incomes were also significantly lower. The kernel density functions of per capita family incomes clearly show that the distribution of eligible households that accessed the AUH is further to the left in relation to the rest of the households, followed by eligible nonbeneficiary households and then by non-eligible nonbeneficiary households with children and adult-only households (see figure 2). This suggests that the AUH has been mainly focused on households at the lower end of the income distribution.

Owing to lower family income levels, beneficiary households exhibited higher rates of poverty and extreme poverty. In 2009, $74 \%$ of those households were poor, compared with $65 \%$ of non-beneficiary households. In the case of extreme poverty, the figures are $31 \%$ and $26 \%$ for beneficiary and non-beneficiary households, respectively.

FIGURE 2

Kernel density curves: per capita family income, third quarter of 2009 (Argentine pesos)

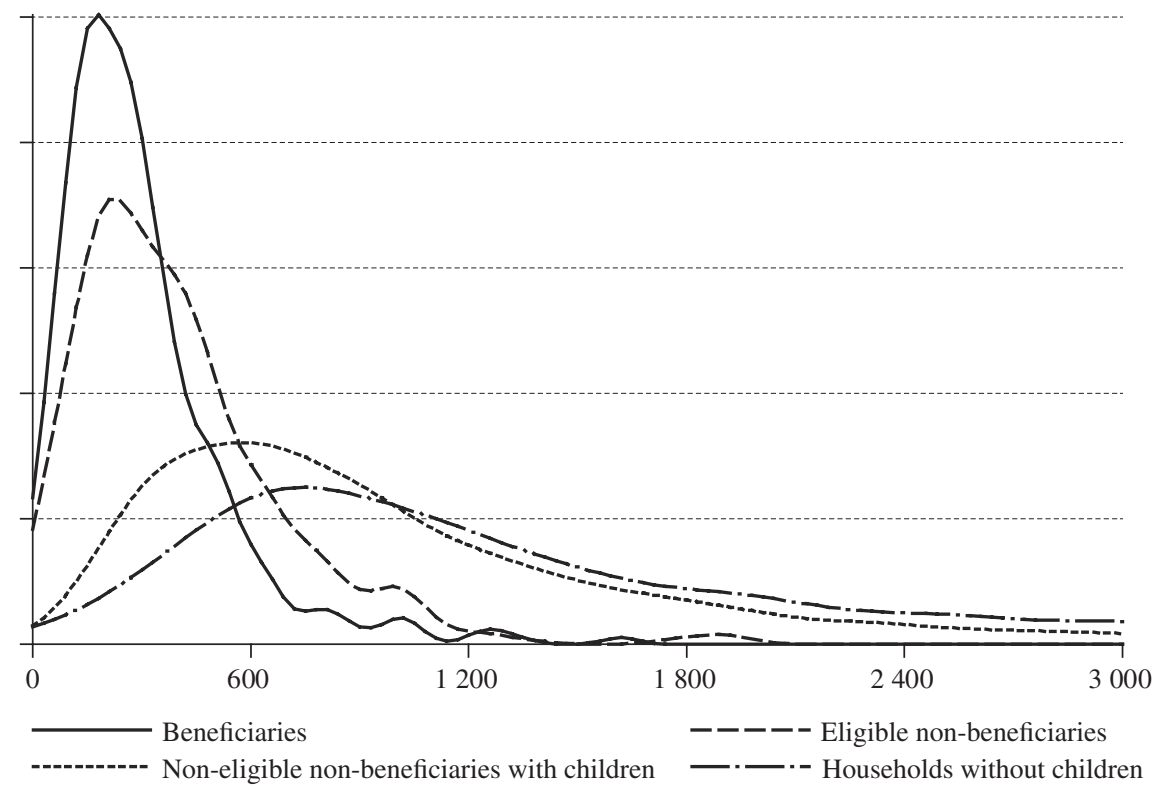

Source: prepared by the authors on the basis of data from the Permanent Household Survey of the National Institute of Statistics and Censuses (INDEC). 
Since about $92 \%$ of beneficiaries are heads of household or spouses, annex table A.2 compares the characteristics of these individuals to those of their counterparts in non-beneficiary households. No statistically significant differences were found in the percentage of female spouses in both sets of households. The differences in the percentage of female heads of household in the treated and control groups were not significant either.

Both heads of household and spouses in households that gained access to the AUH in 2010 had lower average ages than those in the other group of households in 2009. The educational level of household heads and spouses in beneficiary households was also significantly lower, on average, than in the other households.
Lastly, no significant differences were found between the spouses of both groups when it came to labour participation rates and composition. The behaviour of heads of both types of households regarding these variables was no different either. However, the opposite is observed for the hourly intensity of spouses: those living in beneficiary households worked, on average, fewer hours (-5.8 per week) than spouses in non-beneficiary households in 2009.

To sum up, the two groups of households exhibited differences in some observable variables before the programme was launched. Such pre-existing dissimilarities will be taken into account in the econometric analysis in order to accurately estimate the impacts of the AUH on labour-market outcomes.

\section{VII}

\section{Econometric results}

This section analyses the econometric results derived from the difference-in-difference estimator (DD) calculated using pooled panels of micro-data from the three first quarters of 2009 and 2010. As mentioned earlier, this estimator is applied to all households with children that were eligible in 2009, some of which became AUH beneficiaries in 2010 and some of which did not access the programme.

The analysis is carried out at three levels of comparison: (i) beneficiary households vs. nonbeneficiary eligible households; (ii) members of each of those households (beneficiary and non-beneficiary), differentiating by gender and by whether they are heads or spouses; and (iii) beneficiaries vs. comparable individuals living in households in the control group. ${ }^{12}$

\section{Beneficiary households vs. eligible non- beneficiary households}

Annex table A. 3 presents the results of the estimations at the household level. For each outcome variable, it shows the mean change for the treatment and control groups,

\footnotetext{
12 The results of the Logit models used to calibrate scores are not included owing to space restrictions. They are available upon request, however.
}

the ATT, the bootstrap standard errors, ${ }^{13}$ the p-values and the number of observations included in each group.

Even though the sign of the ATT parameters relating to labour-market variables suggests that the AUH has a negative impact on economic participation decisions -measured by the proportion of active members to total adult members - and on the household employment rate, these changes are not statistically significant under either of the two matching alternatives employed (NN and LLR). Likewise, no significant impact is observed on the incidence of unemployment or on the average number of hours worked by the employed members of the household.

In the same manner, differences regarding the behaviour of total and per capita family incomes between beneficiary households and those in the control group are not statistically different from zero. However, this common pattern observed in the dynamics of total incomes of both groups of households is, in fact, the result of greater increases in non-labour incomes that offset the somewhat weaker dynamism of labour incomes in beneficiary households vis-à-vis the control group. The negative ATT coefficient of labour incomes turns out to be

\footnotetext{
13 The theoretical standard errors were also computed, but they are not presented here because there were no significant differences from the bootstrap standard errors.
} 
significant only at the $10 \%$ level of significance under LLR. The results concerning non-labour incomes, however, are significant at $1 \%$ in both matching alternatives, mainly as a result of the AUH.

To sum up, the lack of statistical significance in the labour-market results would seem to suggest that AUH implementation has not created any major disincentives to work among adults in the short term (considering that panel data used in this study only follows households for a few quarters). However, at the household level, this situation could be a net result of different effects of the AUH on its members. In order to analyse these findings in greater detail, the results of the estimations carried out separately for different adult members of the households are presented below.

\section{Beneficiary household members vs. members of eligible non-beneficiary households}

Table 2 presents the composition of beneficiary households by gender and household position of the adult members. As may be observed, the most important groups are: (i) total heads and spouses; (ii) women; (iii) female spouses; (iv) heads; (v) female heads; (vi) male heads. For this reason, at the individual level the analysis will be limited to these groups, who will be compared to their counterparts in the control group households.

TABLE 2

Composition of members in beneficiary
households, by gender and household
position, 2010
(Percentages)

\begin{tabular}{lrcc}
\hline & Men & Women & Total \\
\hline Heads & 31 & 14 & 45 \\
Spouses & 3 & 30 & 33 \\
$\quad$ Subtotal & 34 & 44 & 78 \\
Children & 8 & 10 & 18 \\
Other members & 2 & 2 & 4 \\
$\quad$ Total & 44 & 56 & 100 \\
\hline
\end{tabular}

Source: prepared by the authors on the basis of data from the Permanent Household Survey of the National Institute of Statistics and Censuses (INDEC).

Annex table A.4 presents the econometric estimates for these six groups. The results at this level of analysis are consistent with those obtained at the household level in that the majority of beneficiary household members do not behave significantly differently from household members in the control group. In particular, the ATTs corresponding to the activity and employment conditions are not statistically significant for all household members and under the two matching techniques employed. However, the relative increase observed in the unemployment rate among female spouses in beneficiary households is statistically significant at the $5 \%$ or $10 \%$ level, depending on the matching technique employed.

With regard to the average hours worked (calculated only for those individuals that are employed in both observations), it is notable that, even though the number of hours worked by women in beneficiary households decreases while the opposite occurs in non-beneficiary households, the average differences between the two groups are not statistically significant, and are not so for the rest of the members considered.

With regard to family income variations and their sources, the greater increase in non-labour incomes registered among AUH beneficiary households is a result of what happened among women in general and among female spouses in particular. This is consistent with the fact that women represent about $90 \%$ of total AUH beneficiaries. The very low or null significance found for the differences in labour incomes at the household level is also confirmed at the individual level. As a result of this, the differences observed in non-labour incomes translate into the dynamics of total income gaps. In fact, women in general and female spouses in particular (in the case of $\mathrm{NN}$ ) experience significant increases in total individual incomes as a consequence of receiving the AUH.

In summary, as with previous results, the findings relating to household members do not allow us to conclude that receiving a monetary transfer such as the AUH represents a disincentive to participate in the labour market or reduce the number of hours worked for those that continue to be employed in the short term.

\section{Female AUH beneficiaries (heads of household or spouses) vs. women in eligible non- beneficiary households}

Lastly, we evaluate the AUH by comparing beneficiaries' behaviour with that of household members in the control group. The difference with the previous exercise is that we compared the members of beneficiary households to those of the control group without identifying the beneficiaries in the first group.

Given that almost all beneficiaries are women, the analysis will be restricted to this subgroup of individuals. In particular, work decisions and income generation are evaluated for all female beneficiaries (and compared with those of adult women in eligible non-beneficiary 
households) and then for heads of household and spouses separately. In the latter two cases the comparison is carried out with respect to female heads and spouses of households in the control group, respectively.

The results are presented in annex table A.5. Once again they confirm that the AUH had no significant effects on work decisions between 2009 and 2010. In particular, this programme does not seem to have encouraged net exits towards inactivity or caused a reduction in the number of hours worked by women, and thus it did not lead to a decrease in their labour supply (among both heads of households and spouses). It is important to note that the relative increase observed in the unemployment rate of women in beneficiary households (although the difference between both groups was significant only at the 5\%/10\% levels) becomes negligible when the analysis is restricted to female beneficiaries. The ATT is significant only at the $10 \%$ level in the case of LLR.

\section{VIII}

\section{Conclusions}

The introduction of the AUH represents a major step forward in meeting the challenges involved in closing the social protection child coverage gap in Argentina. This programme has a direct connection with the contributory social security system in that it extends the existing system of family allowances for children and adolescents available to workers in the formal economy.

This study is the first to measure the impacts of the AUH on adult labour participation, employment, unemployment, hours worked, and labour and non-labour income generation, by using the difference-in-difference estimator and propensity score matching techniques.

On the basis of the results obtained, it cannot be concluded that this programme generated short-term disincentives to work among the adult members of beneficiary households between 2009 and 2010, in terms of encouraging them to leave the labour force or reduce the number of hours worked. These results are consistent with much of the empirical evidence for similar transfer programmes in other Latin American countries and they are highly relevant to the discussion surrounding the design of social public policies in the region, given that any potential negative side effects
The absence of significant effects of the AUH on work decisions is consistent with the null impact of the programme on female beneficiaries' labour incomes. In fact, a significant double-difference estimated average effect is found in the case of non-labour incomes of beneficiaries (in particular, of those who are spouses) as a result of receiving the benefit which, in the absence of negative changes to other income sources, results in net increases of total incomes received by beneficiaries. ${ }^{14}$

\footnotetext{
14 The estimates have been based on the comparison of those groups of households and individuals that remain in the sample after the exclusions mentioned in section III. However, there are some beneficiaries inside the common support region whose probabilities of being treated are close to zero. Following Heckman, Ichimura and Todd (1997), we use the trimming method to avoid the biases that might arise in the estimates when including these cases. The results support earlier conclusions.
}

of these programmes on the labour market must be minimized, and that these kinds of cash transfers have acquired increasing relevance as a constitutive part of the social protection system.

However, at least four caveats apply to our conclusions. First, unlike other studies that perform impact assessments as part of their evaluation of this kind of programme, no surveys have been specifically designed for this purpose in Argentina. Second, in the household survey employed, AUH beneficiaries are only indirectly identified. Third, differences in unobserved characteristics might arise between the treatment and control groups, although the differences-in-differences methodology aims to reduce the likelihood of this problem. Lastly, this paper covers a relatively short period of time, and the impacts on labour-market participation could change when analysing a longer time horizon.

Hence, reliable and updated information is essential to perform continuous follow-up and an accurate assessment of the possible impacts of the AUH and other social protection programmes. Argentina presents significant lags in this area compared to other countries in the region that have similar income levels and social security developments. 
Moreover, even though AUH implementation marks a significant improvement in social coverage for children, important challenges remain. For example, the programme excludes informal workers who earn more than the minimum wage. Insofar as the AUH is considered an extension of the contributory scheme, progress should be made towards standardizing the requirements of the two schemes, particularly the upper earnings limit, which is currently significantly higher in the contributory system than in the AUH regime.

With regard to meeting the conditionalities for accessing the cash benefit, the availability of health centres and educational establishments in the beneficiaries' neighbourhoods and surrounding areas must be considered, along with the quality of the services they provide.
Also, AUH regulations state that beneficiaries may not participate in any other social assistance programmes. This regulation seems reasonable when the benefit replaces other programmes that target similar needs. However, this does not take into account that other cash transfer programmes have different objectives: for example, some seek to improve the employability of unemployed workers or workers in the informal economy. Therefore, progress should be made towards integrating and articulating the various components of the social protection system.

Lastly, all these policies should be framed within a long-term economic development strategy built on the basis of an integrated production structure that leads to high efficiency, systemic competitiveness and increased labour demand.

ANNEX

TABLE A. 1

Characteristics of AUH beneficiaries and non-beneficiaries, 2010

\begin{tabular}{|c|c|c|c|c|c|c|}
\hline \multirow{2}{*}{ Characteristics } & \multicolumn{3}{|c|}{ Beneficiaries } & \multicolumn{3}{|c|}{ Non-beneficiaries (active) } \\
\hline & Total & Women & Men & Total & Women & Men \\
\hline \multicolumn{7}{|l|}{ Family relationship } \\
\hline Head & $33.6 \%$ & $26.8 \%$ & $88.5 \%$ & $41.9 \%$ & $19.8 \%$ & $69.3 \%$ \\
\hline Spouse/partner & $57.9 \%$ & $64.3 \%$ & $6.2 \%$ & $34.9 \%$ & $57.8 \%$ & $6.7 \%$ \\
\hline Other members & $8.5 \%$ & $8.9 \%$ & $5.3 \%$ & $23.2 \%$ & $22.4 \%$ & $24.1 \%$ \\
\hline Age & 35.1 & 34.6 & 38.8 & 35.9 & 35.4 & 36.6 \\
\hline Years of education & 9.6 & 9.6 & 9.4 & 11.4 & 11.8 & 10.9 \\
\hline \multicolumn{7}{|l|}{ Employment status } \\
\hline Employed & $47.1 \%$ & $41.8 \%$ & $89.6 \%$ & $65.7 \%$ & $49.1 \%$ & $86.3 \%$ \\
\hline Unemployed & $6.6 \%$ & $6.7 \%$ & $5.6 \%$ & $5.3 \%$ & $5.5 \%$ & $5.2 \%$ \\
\hline Inactive & $46.4 \%$ & $51.6 \%$ & $4.8 \%$ & $29.0 \%$ & $45.4 \%$ & $8.6 \%$ \\
\hline Hours worked & 30.0 & 26.6 & 43.0 & 40.0 & 31.5 & 45.9 \\
\hline \multicolumn{7}{|l|}{ Gender } \\
\hline Women & $88.9 \%$ & & & $55.3 \%$ & & \\
\hline \multicolumn{7}{|l|}{ Household members (average) } \\
\hline Members 0-5 & 1.4 & & & 1.3 & & \\
\hline Members 6-12 & 1.6 & & & 1.4 & & \\
\hline Members $13-17$ & 1.4 & & & 1.4 & & \\
\hline Members 18-59/64 & 2.2 & & & 2.3 & & \\
\hline No. of children & 2.5 & & & 2.0 & & \\
\hline Total & 4.7 & & & 4.4 & & \\
\hline Poor household & $63.7 \%$ & & & $26.1 \%$ & & \\
\hline Extremely poor household & $17.9 \%$ & & & $7.1 \%$ & & \\
\hline Children covered by AUH & 2.1 & & & & & \\
\hline Amount of AUH benefit & 305.08 & & & & & \\
\hline Amount of AUH benefit/family income & $38.5 \%$ & & & & & \\
\hline Poverty gap (net family income) & $45.0 \%$ & & & & & \\
\hline Poverty gap (family income) & $38.0 \%$ & & & & & \\
\hline
\end{tabular}

Source: prepared by the authors on the basis of data from the Permanent Household Survey of the National Institute of Statistics and Censuses (INDEC). 
TABLE A.2

Characteristics of AUH beneficiaries and non-beneficiaries, 2009

\begin{tabular}{|c|c|c|c|c|}
\hline Characteristics & Non-beneficiaries & Beneficiaries & \multicolumn{2}{|c|}{ Difference } \\
\hline \multicolumn{5}{|l|}{ Household } \\
\hline Members & 4.6 & 4.8 & -0.13 & \\
\hline Children & 2.3 & 2.6 & -0.31 & $* * *$ \\
\hline Total income (Argentine pesos) & 1253.5 & 1130.7 & 122.9 & $* * *$ \\
\hline Labour income (Argentine pesos) & 290.3 & 251.6 & 38.7 & $* * *$ \\
\hline Per capita income (Argentine pesos) & 1112.2 & 979.9 & 132.2 & $* * *$ \\
\hline Non-labour income (Argentine pesos) & 141.4 & 150.7 & -9.4 & \\
\hline Poor & $65.1 \%$ & $74.4 \%$ & -9.3 p.p. & $* * *$ \\
\hline Extremely poor & $26.2 \%$ & $30.5 \%$ & -4.4 p.p. & $* *$ \\
\hline \multicolumn{5}{|l|}{ Head } \\
\hline Women & $64.9 \%$ & $68.5 \%$ & -3.5 p.p. & \\
\hline Age & 39.9 & 37.5 & 2.3 & $* * *$ \\
\hline Years of education & 9.3 & 9.0 & 0.3 & ** \\
\hline \multicolumn{5}{|l|}{ Employment status } \\
\hline Employed & $80.5 \%$ & $79.4 \%$ & 1.1 p.p. & \\
\hline Unemployed & $6.5 \%$ & $8.5 \%$ & -2.0 p.p. & $*$ \\
\hline Inactive & $13.0 \%$ & $12.1 \%$ & 0.9 p.p. & \\
\hline Hours worked & 42.0 & 42.2 & -0.2 & \\
\hline \multicolumn{5}{|l|}{ Spouse } \\
\hline Women & $8.2 \%$ & $7.8 \%$ & 0.4 p.p. & \\
\hline Age & 36.1 & 34.1 & 1.9 & $* * *$ \\
\hline Years of education & 10.0 & 9.4 & 0.6 & $* * *$ \\
\hline \multicolumn{5}{|l|}{ Employment status } \\
\hline Employed & $41.1 \%$ & $41.2 \%$ & -0.1 p.p. & \\
\hline Unemployed & $6.1 \%$ & $5.1 \%$ & 1.0 p.p. & \\
\hline Inactive & $52.8 \%$ & $53.7 \%$ & -0.9 p.p. & \\
\hline Hours worked & 33.6 & 27.8 & 5.8 & $* * *$ \\
\hline
\end{tabular}

Source: prepared by the authors on the basis of data from the Permanent Household Survey of the National Institute of Statistics and Censuses (INDEC).

Note: $* * *$ p-value $<0.01 ; * *$ p-value $<0.05 ; *$ p-value $<0.1 ;$ p.p. $=$ percentage points. 


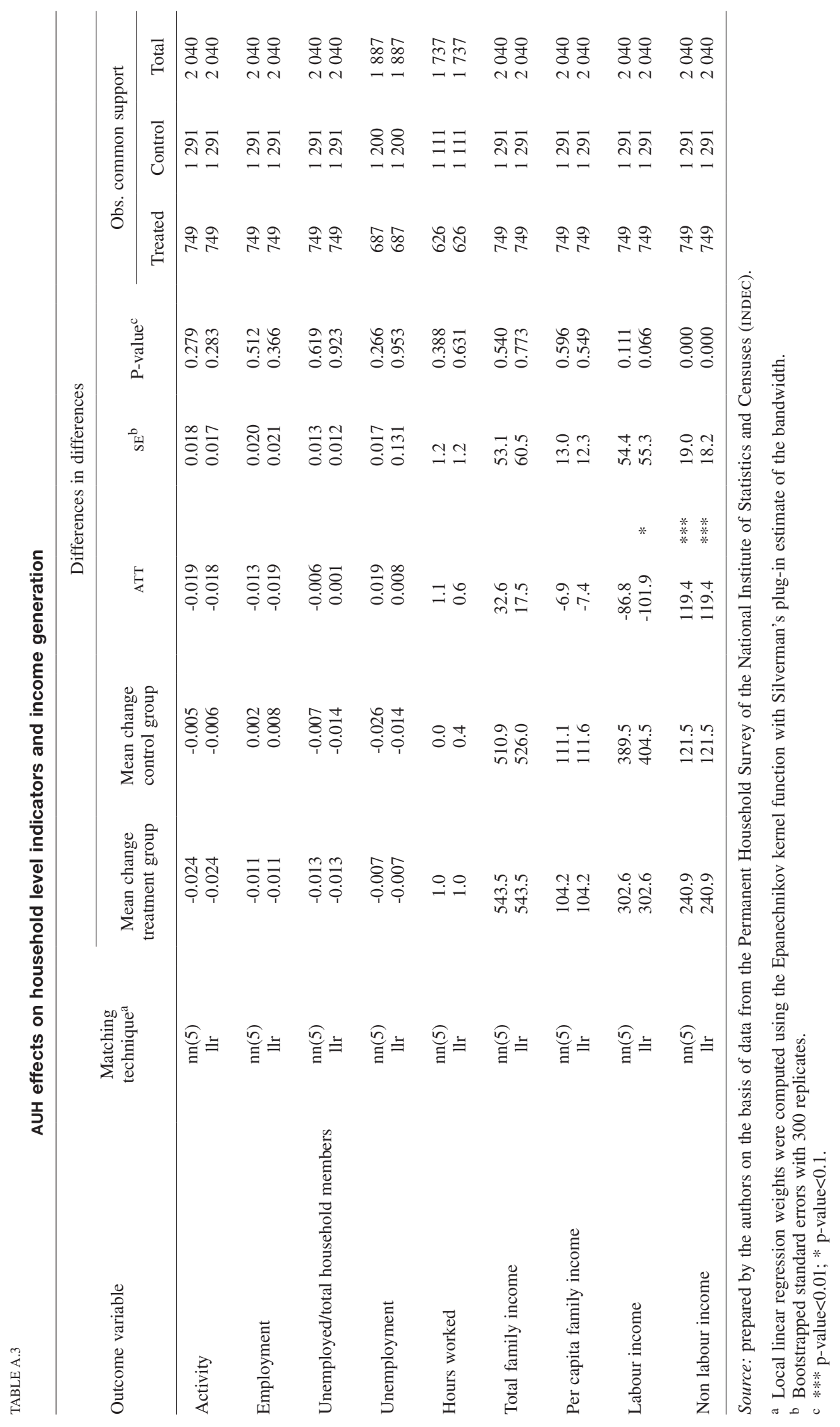




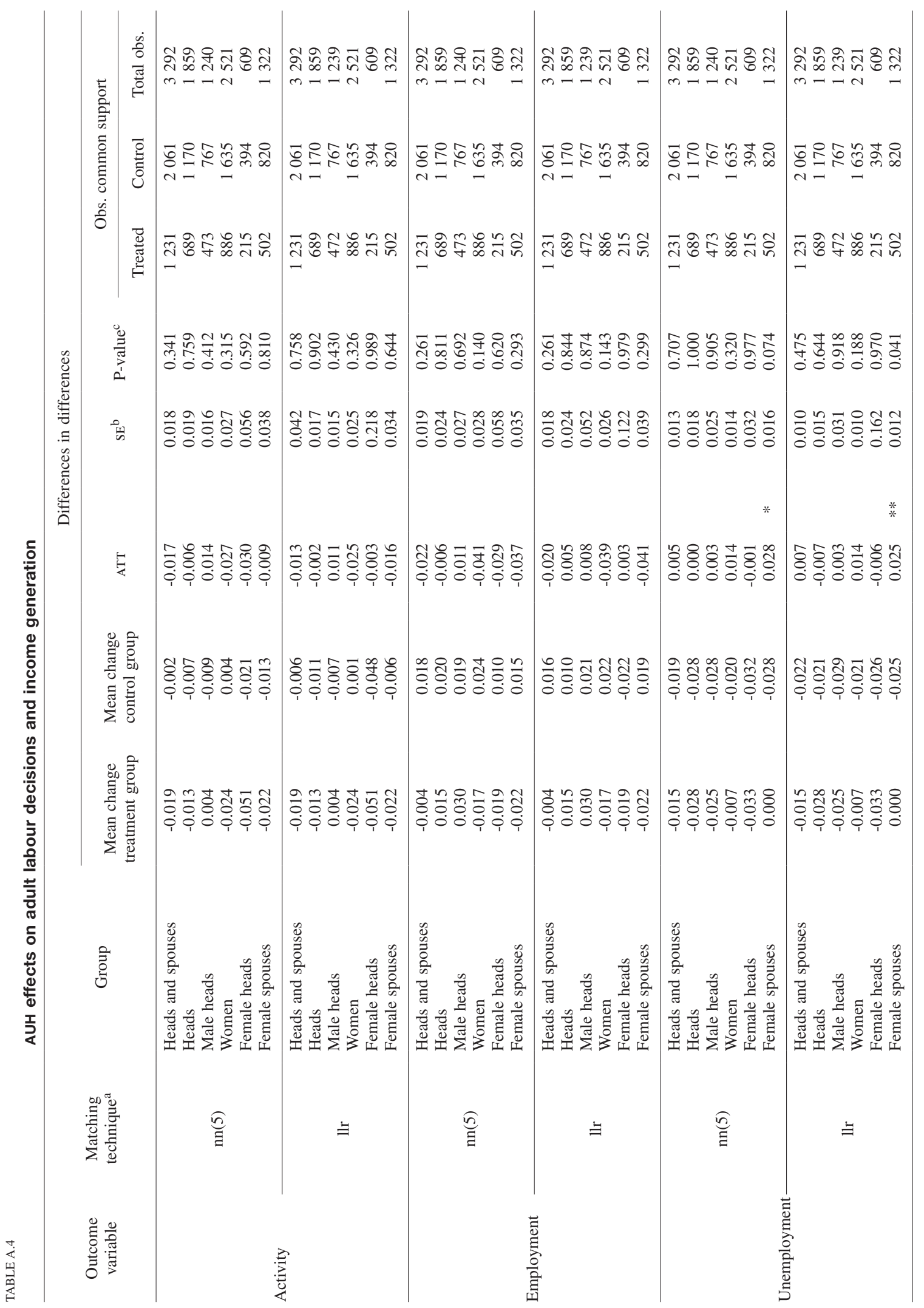




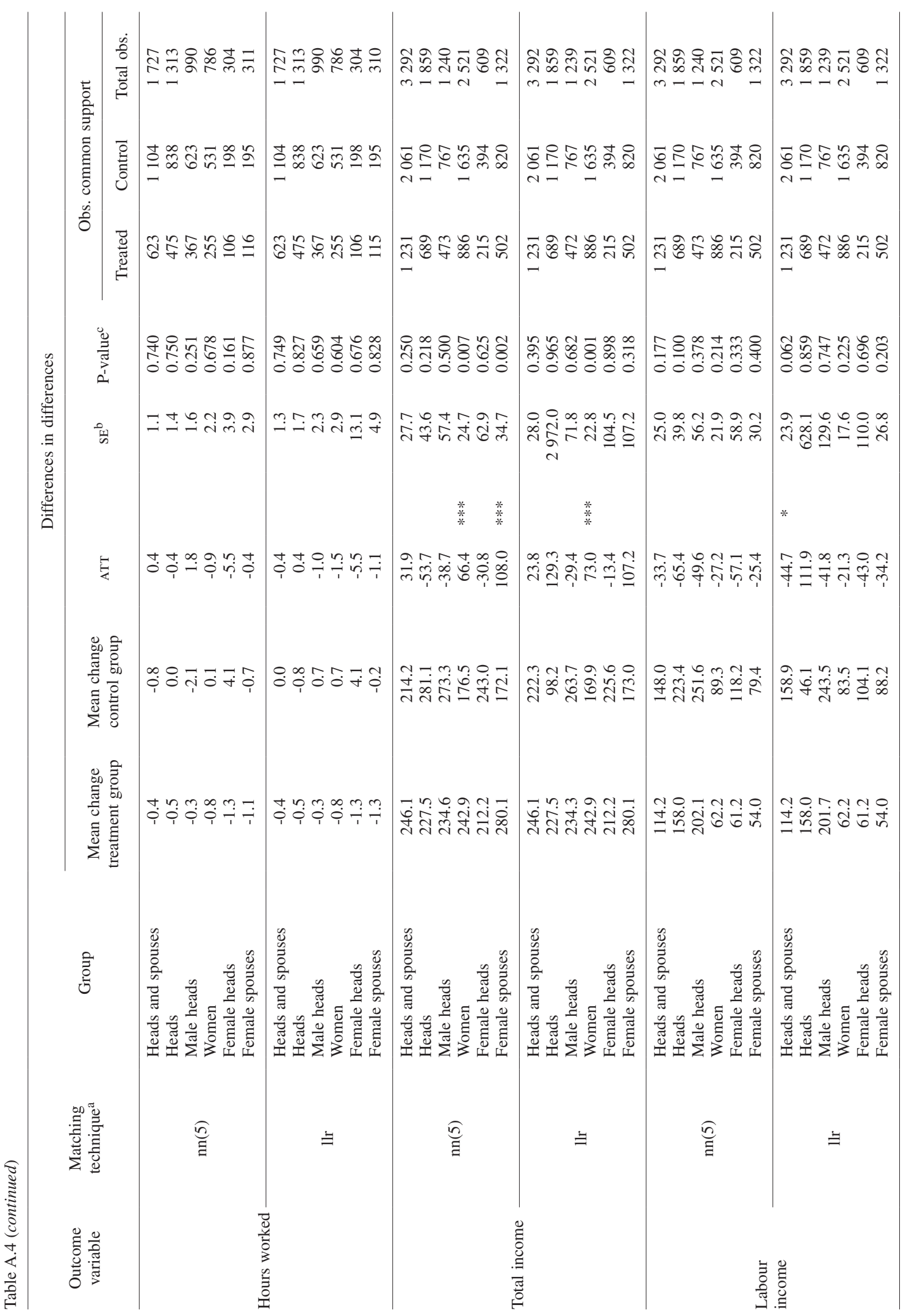









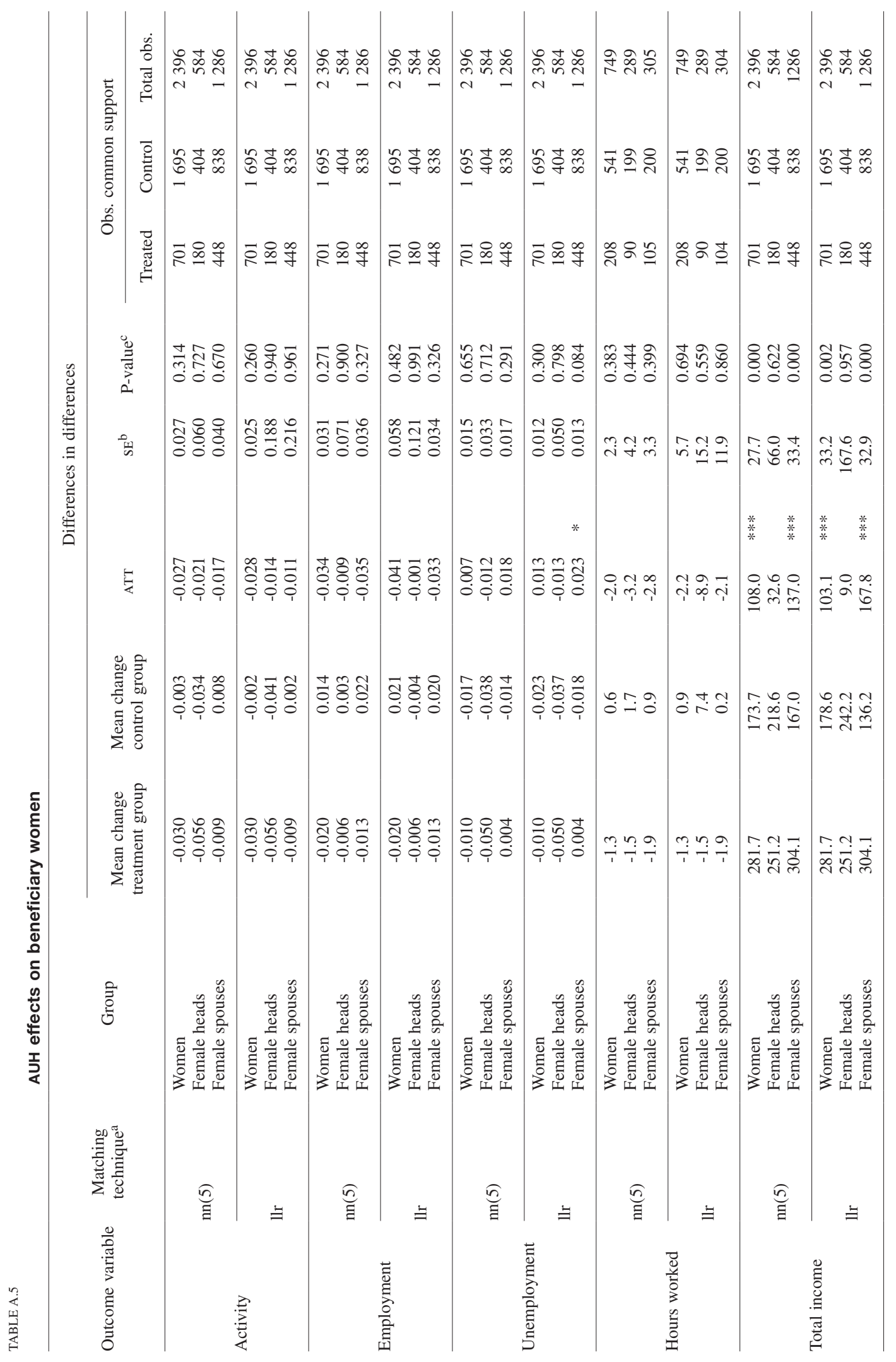




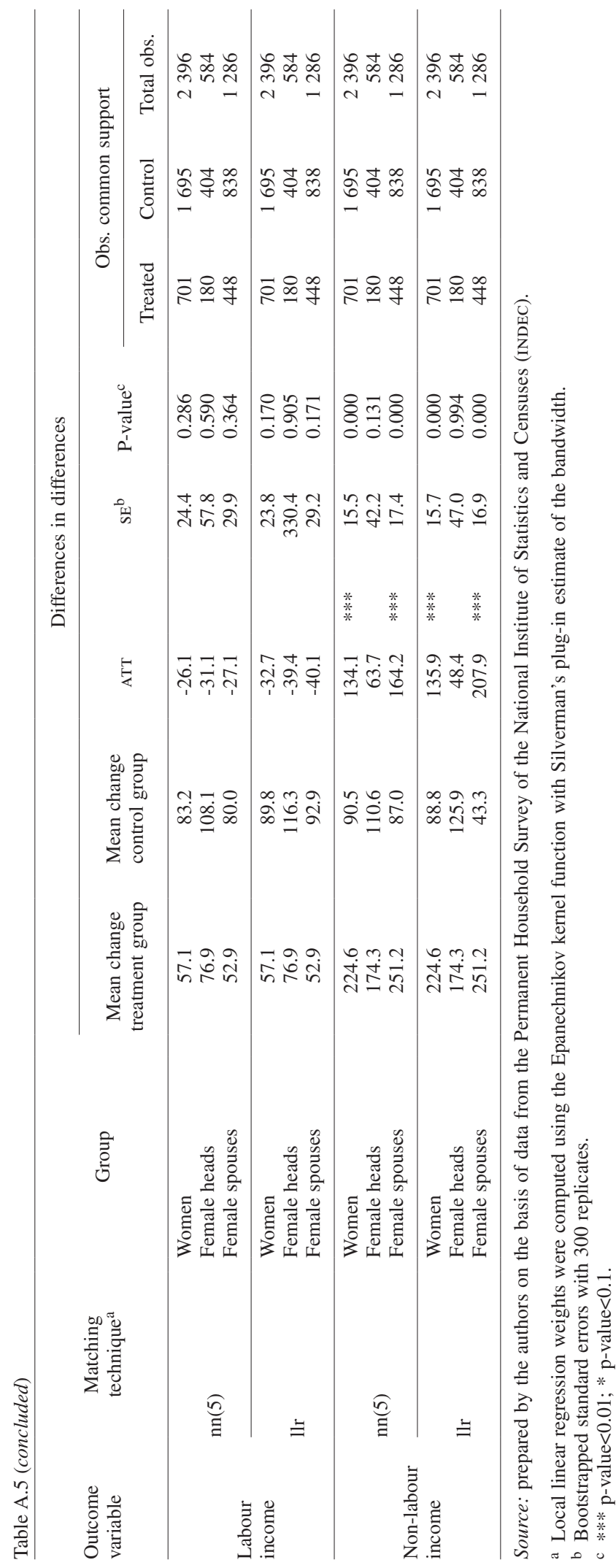




\section{Bibliography}

Agis, E., C. Cañete and D. Panigo (2010), "El impacto de la asignación universal por hijo en Argentina", Centre for the Study of Argentinean Development (CENDA)/Programa de Formación Popular en Economía (PROFOPE)/Centre of Labour Study and Research - Program for Economic Research on Technology, Work and Employment (CEIL-PIETTE).

Alzúa, M., G. Cruces and L. Ripani (2010), "Welfare programmes and labour supply in developing countries. Experimental evidence from Latin America”, Working Paper, No. 95, La Plata, Centre for Distributive, Labour and Social Studies (CEDLAS), National University of La Plata.

Amarante, V., M. Ferrando and A. Vigorito (2011), "School attendance, child labour and cash transfers: an impact evaluation of PANEs", Working Paper, No. 22/11, Poverty and Economic Policy Network-PIERI.

Ashenfelter, O. (1978), "Estimating the effect of training programmes on earnings", Review of Economics and Statistics, vol. 60, No. 1, Cambridge, Massachusetts, MIT Press.

Bertranou, F. and R. Maurizio (2012), "Semi-conditional cash transfers in the form of family allowances for children and adolescents in the informal economy in Argentina", International Social Security Review, vol. 65, No. 1, Geneva, International Social Security Association.

Duflo, E. (2001), "Schooling and labour market consequences of school construction in Indonesia: evidence from an unusual policy experiment", American Economic Review, vol. 91, No. 4, Nashville, Tennessee, American Economic Association.

Fan, J. (1992), “Design-adaptive nonparametric regression", Journal of the American Statistical Association, vol. 87, No. 420, Alexandria, American Statistical Association, December.

Ferro, A., A. Kassouf and D. Levison (2010), "The impact of conditional cash transfer programmes on household work decisions in Brazil", Child Labour and the Transition between School and Work, Research in Labour Economics, R. Akee, E. Edmonds and K. Tatsiramos (eds.), Emerald Group Publishing Limited.

Ferro, A. and A. Nicollela (2007), "The Impact of Conditional Cash Transfers Programmes on Household Work Decision in Brazil" [online] http://www.iza.org/conference_files/worldb2007/ ferro_a3468.pdf.

Foguel, M. and R. Paes de Barros (2010), "The effects of conditional cash transfer programmes on adult labour supply: an empirical analysis using a time-series-cross-section sample of Brazilian municipalities", Estudos Econômicos, vol. 40, No. 2, São Paulo, University of São Paulo.

Galasso, M. (2006), "With their effort and one opportunity: alleviating extreme poverty in Chile", Documento de Trabajo, Washington, D.C., World Bank.

Galasso, M. and M. Ravallion (2004), "Social protection in a crisis: Argentina's Plan Jefes y Jefas", The World Bank Economic Review, vol. 18, No. 3, Washington, D.C., World Bank.

Gammage, S. (2010), "Time pressed and time poor: unpaid household work in Guatemala", Feminist Economics, vol. 16, No. 3, Taylor \& Francis.

Garganta, S. and L. Gasparini (2012), "El impacto de un programa social sobre la informalidad laboral: El caso de la AUH en Argentina", Working Paper, No. 133, La Plata, Centre for Distributive, Labour and Social Studies (CEDLAS), National University of La Plata.

Gasparini, L. and G. Cruces (2010), "Las asignaciones universales por hijo: Impacto, discusión y alternativas", Working Paper, No. 102, La Plata, Centre for Distributive, Labour and Social Studies (CEDlas), National University of La Plata.
Heckman, J., H. Ichimura and P. Todd (1998), "Matching as an Econometric Evaluation Estimator", The Review of Economic Studies, vol. 65, No. 2, Oxford, Oxford University Press.

(1997), "Matching as an econometric evaluation estimator: evidence from evaluating a job training programme", The Review of Economic Studies, vol. 64, No. 4, Oxford, Oxford University Press.

Heckman, J. and J. Smith (1999), “The pre-programme earnings dip and the determinants of participation in a social programme. Implications for simple programme evaluation strategies", The Economic Journal, vol. 109, No. 457, Wiley.

ILo (International Labour Organization) (2010), Aportes para la construcción de un piso de protección social en Argentina: El caso de las asignaciones familiares, Buenos Aires, ILO Country Office for Argentina.

Killingsworth, M. (1983), Labour supply, Cambridge, Massachusetts, Cambridge University Press.

Medeiros, M., T. Britto and F. Veras Soares (2008), "Targeted cash transfer programmes in Brazil: BPC and the Bolsa Família", Working Paper, No. 46, Brasilia, International Policy Centre for Inclusive Growth.

Moffit, R. (2002), "Welfare programmes and labour supply", NBER Working Paper, No. 9168, Cambridge, Massachusetts, National Bureau of Economic Research.

Parker, S. and E. Skoufias (2000), "The impact of PROGRESA on work, leisure, and time allocation", Working Paper, Washington, D.C., International Food Policy Research Institute.

Pautassi, L., P. Arcidiácono and M. Straschnoy (2013), "Asignación universal por hijo para la protección social de la Argentina. Entre la satisfacción de necesidades y el reconocimiento de derechos", Políticas Sociales series, No. 184 (LC/L.3662), Santiago, Chile, Economic Commission for Latin America and the Caribbean (ECLAC).

Ravallion, M. and Q. Wodon (2000), "Does child labour displace schooling? Evidence on behavioural responses to an enrollment subsidy", The Economic Journal, vol. 110, No. 462, Royal Economic Society, March.

Roca, E. (2010), "Ingreso universal por hijo para protección social", paper presented at the international workshop "Sharing Innovative Experiences: Successful Social Protection Floor Experiences", Turin, International Training Centre.

Skoufias, E. and V. Di Maro (2008), "Conditional cash transfers, adult work incentives, and poverty", Journal of Development Studies, vol. 44, No. 7, Taylor \& Francis, July.

Skoufias, E. and S. Parker (2001), "Conditional cash transfers and their impact on child work and schooling", FCND Discussion Paper, No. 123, Washington, D.C., International Food Policy Research Institute.

Soares, F., R. Ribas and G. Hirata (2008), "Achievements and shortfalls of conditional cash transfers: impact evaluation of Paraguay's Tekoporã Programme", IPC Evaluation Note, No. 3, Brasilia, International Poverty Centre.

Soares, F., R. Ribas and R. Osório (2007), "Evaluating the impact of Brazil's Bolsa Família: cash transfer programmes in comparative perspective", IPC Evaluation Note, No. 1, Brasilia, International Poverty Centre.

Tavares, P. (2008), "Efeito do Programa Bolsa Família sobre a oferta de trabalho das mães", Anais do XXXVI Encontro Nacional de Economia, Rio de Janeiro, National Association of Centers for Post-graduation in Economics (ANPEC).

Teixeira, C. (2010), "A heterogeneity analysis of the Bolsa Família Programme effect on men and women's work supply", Working Paper, No. 61, Brasilia, International Policy Centre for Inclusive Growth. 